Cite this article as:

Brandmo, C., Aas, M., Colbjørnsen, T., \& Olsen, R. (2019). Group Coaching that Promotes Self-Efficacy and Role Clarity among School Leaders. Scandinavian Journal of Educational Research, 1-17. doi:10.1080/00313831.2019.1659406

(NB! Check doi location https://doi.org/10.1080/00313831.2019.1659406 for updates concerning year, volum, issue and pages)

\title{
Group Coaching that Promotes Self-Efficacy and Role Clarity among School Leaders
}

\author{
Christian Brandmo ${ }^{1}$, Marit Aas $^{2}$, Tor Colbjørnsen ${ }^{3}$, and Rolf Olsen ${ }^{4}$ \\ ${ }^{1}$ Department of Special Needs Education, University of Oslo, Norway \\ ${ }^{2}$ Department of Primary and Secondary Teacher Education, Oslo Metropolitan University, \\ Norway \\ ${ }^{3}$ Department of Teacher Education and School Research, University of Oslo, Norway \\ ${ }^{4}$ Result Oriented Development Consulting, Norway
}

Address for correspondence: Christian Brandmo, Department of Special Needs Education, P.O. Box 1140 Blindern, NO-0318 Oslo, Norway

Phone: + 47228552 43, Fax: + 47228580 21, E-mail: christian.brandmo@isp.uio.no 


\begin{abstract}
Group coaching is emerging as an approach with a strong potential for developing leadership competencies. However, there is little research on its use in the professional training of school leaders. In this study, we investigate the outcome of and the processes involved in group coaching using data from reflection papers and evaluations. The results suggest that group coaching fosters self-efficacy and promotes a clearer understanding of the school leaders’ role. Moreover, the study suggests that theory from the field of psychotherapy can be a useful analytical tool for studying the processes that go on within group coaching.
\end{abstract}

Keywords: group coaching, school leadership, self-efficacy, role clarity, psychotherapeutic factors 


\section{Group Coaching that Promotes Self-Efficacy and Role Clarity among School Leaders Introduction}

Coaching contains of communicative interaction between two or more people with the aim of unlocking the individuals' potential to maximize their own performance (Whitmore, 2002). Today, coaching is conducted in variety of contexts, for instance in sport (Gjesdal, Wold, \& Ommundsen, 2018; Stelter, Nielsen, \& Wikman, 2011), in social work (Ryom, Andersen, \& Stelter, 2017), in organizations (Brown \& Grant, 2010), and in the business sector (Whitmore, 2009), as well as in education (Fletcher \& Mullen, 2012) and health care (Wolever, Moore, \& Jordan, 2017). Moreover, coaching may have multiple purposes that are related to both individual and organizational goals of change, growth, or development (e.g., mindfulness, well-being, professional development, career-change, leadership development, teambuilding, and development of organizations) (Drake \& Pritchard, 2017; Korotow, 2017; Parker, 2017; Smith, 2017; Tschannen-Moran \& Tschannen-Moran, 2010). Modern forms of coaching are often traced back to humanistic psychology (e.g., Maslow, 1968) and the human potential movement of the 1960s (Grant, 2007). Coaching is not a unified approach or method, rather it is a collection of various practices, approaches, and perspectives (Bachkirova, Spence, \& Drake, 2017; Palmer \& Whybrow, 2007), which in turn can be based on a variety of philosophical and psychological underpinnings (Law, Ireland, and Hussain, 2007).

In the current study, we explore group coaching in the context of a training program for school leaders. Thus far, coaching in school leadership programs has been presented mainly as a one-on-one individualized approach involving a leader and either an internal coach or a coach from outside of the leadership program (Rhodes, 2012; Watling \& Gasper, 2012). Group coaching is an alternative approach, where a coach and two or more people work together toward one or multiple goal(s) (Cockerham, 2011). Now, coaches around the 
world are adding this approach as a new modality to their work (Britton, 2010). In spite of the limited research on group coaching, literature reviews suggest that this form of coaching can be beneficial for numerous skills and qualities, such as developing an understanding and selfregulation of acceptable group behaviors; development of trust and support within the group; improved listening and communication; supporting social capital and social resilience; appreciation and alignment of individual goals, strengths, and values; leadership development; improved systemic awareness of the organization; and organizational change (Brown \& Grant, 2010; Ryom et al., 2017; Stelter et al., 2011). However, group coaching has also been described as challenging because it involves complex social interaction and often explores issues normally avoided by the group (Brown \& Grant, 2010). Participants can become anxious or feel discomfort when the conversation turns to topics that are difficult or private; moreover, tension within the group or feelings of insecurity can prevent openness and lead to a destructive outcome if the coach does not properly handle the situation. At the same time, and quite paradoxically, many practitioners and researcher assume that the presence of discomfort often is what promotes real change (Brown \& Grant, 2010).

Given that there still is little research on group coaching and its outcomes, particularly in the context of school leadership, the aim of this study was to explore the contribution of group coaching within the context of a training program for school leaders as well as try to understand the processes that go on within group coaching. Because self-efficacy and role understanding are considered important for efficient leadership (Federici \& Skaalvik, 2011, 2012; Tschannen-Moran \& Gareis, 2004), we decided to focus particularly on these constructs as potential outcome variables. The field of psychotherapy has a long tradition of describing cognitive and emotional processes that emerge when humans interact within a group and share their experiences (Kivlighan \& Holmes, 2004). Therefore, we wanted to explore whether theory from psychotherapy could be a useful lens for understanding the human 
interplay that goes on within group coaching. Given this, we stated the following research questions:

a) Does group coaching promote self-efficacy and role clarity among school leaders?

b) Can theory from the field of psychotherapy contribute to our understanding of group coaching processes?

\section{Theoretical framework}

\section{Group Coaching}

Because group coaching is a relatively new field of research that draws on a wide range of theories and learning approaches, scholars have not yet agreed on a common definition. Sometimes, the literature distinguishes between group coaching and team coaching (Britton, 2010; Clutterbuck, 2007; Thornton, 2010; Tolhurst, 2010; O’Connor \& Cavanagh, 2017). Team coaching relates to groups in which the individuals are working closely together toward a defined common goal (Brown \& Grant, 2010; Cockerham, 2011). According to Brown and Grant (2010), group coaching is a broader category than team coaching "that relates to any group of individuals, including but not limited to teams, whether participants are working together towards specific goals or not” (2010, p. 32). In the current research, we rely on Cockerham's definition of group coaching: "a facilitated group process that is led by a professional coach and formed with the intention of maximizing the combined energy, experience and wisdom of individuals who chose to join in order to achieve organizational objectives and/or individual goals” (Cockerham, 2011, p. 1). Moreover, we build on the assumption that an individual develops a sense of self and learns through interaction with the other participants.

Regarding the role and function of the coach, some researchers have suggested a distinction between group coaching and group facilitation (Brown \& Grant, 2010; Clutterbuck 2007). According to Clutterbuck (2007), a group coach is a more active member of the group 
that is taking an active part in the dialog and collaborates with the other group-members in approaching the coaching-goal. On the contrary, a group facilitator is focusing mainly on the group process and remains detached from the group. Moreover, Clutterbuck (2007) uses the metaphors "catalyst" and "reagent" to illustrate the difference. While the facilitator is a catalyst that remains largely unchanged, the group coach is a reagent that acquires learning or change through the process. In the group coaching of the current study, the other participants of the group were acting as co-coaches and for that reason the professional coaches were taking both roles, which means they explicitly were switching between taking the role of a catalyst and reagent, dependent on the situation, the fruitfulness of the dialogue, and the progress toward the coaching-goal. It should be noted that the participants were informed about the role-switching practice beforehand, and the group quickly became familiar with the practice. Consequently, the role-switching did not seem to detract the conversation or the ongoing working process.

With regard to coaching in leadership development contexts, there seems to be a consensus in the literature that coaching in general can promote professional development for leaders in several ways (Goff, Guthrie, Goldring, \& Bickman, 2014; Huff, Preston, \& Goldring, 2013; Mavrogordato \& Cannon, 2009; Robertson \& Earl, 2014; Silver, Lochmiller, Copland, \& Tripps, 2009). However, so far, coaching in leadership programs has mainly been regarded as using a dyadic or peer approach, whilst group coaching has been more regularly utilized in the business sector. A main difference between dyadic coaching and group coaching is the group effect, which is the contribution that grows out of the community when leaders representing diverse experiences, backgrounds, contexts, and school cultures meet and interact in a group (Britton, 2015; Thornton, 2010). According to Thornton (2010), the opportunities for learning in such coaching relationships can be multiplied by the number of participants because everyone brings different skills and experiences to the coaching table. 
Consequently, engagement with a range of leaders from various diverse contexts can provide multiple chances for learning and professional development (Flückiger, Aas, Johnson, Lovett, \& Nicolaidou, 2017). For instance, such engagement may give ideas of new ways of working as a leader (Lee, 2007), and it might promote leaders' awareness of how leadership can be performed in different cultures and contexts as well as contribute to the construction of a leadership identity (Aas \& Vavik, 2015). Hence, the literature suggests that group coaching can be beneficial to both individuals and the organization as a whole (Britton, 2010; Brown \& Grant, 2010; Clutterbuck, 2007; O'Connor \& Cavanagh, 2017).

\section{Therapeutic Factors and Group Coaching}

In an attempt to extend our understanding of what actually goes on within group coaching, we turned our attention to theory and research related to psychotherapy. A persuasive body of research has demonstrated that group therapy has been a highly effective form of psychotherapy that provides meaningful benefit for participants (Kivlighan \& Holmes, 2004; McRobert, Burlingame, \& Hoag, 1998). Therapeutic change is an extremely complex process that occurs through an interplay of human experiences, which Yalom and Leszcz (2005, p. 1) refer to as therapeutic factors. See table 1 for an overview of these factors.

\section{[Insert Table 1 about here]}

These factors are interdependent with arbitrary distinctions. The factors each represent different parts of the change process. Some factors (for example, the installation of hope) are cognitive; some factors (for example, imitate behavior) are behavioral; some (for example, catharsis) are emotional; and some (for example, cohesiveness) may be best described as preconditions for change. The various factors are all part of a personal change process (Bloch, Crouch, \& Reibstein, 1981; Vinogradow \& Yalom, 1989). 
Although these identified factors (Yalom \& Leszcz, 2005) have generated considerable clinical and empirical interest, Kivlighan, Miles, and Paquin (2010) pointed out that researchers have not developed theories or models of the interrelationships among the therapeutic factors. Second, and even more important, the relationship between therapeutic factors and outcomes is individualized and assumes that the outcome for a group member is not necessarily the same as the outcome for the group as a whole. This point is relevant for the current study as well, since we report the individual outcomes of group coaching.

Group coaching and group therapy do have some similarities, for instance, both are organized in groups, they are both chaired by a leader (coach or therapist), the group dynamic is considered essential to the outcome, and interaction between the group members follow some kind of rules or procedures (Britton, 2010; Riva, Wachtel, \& Lasky, 2004). However, group coaching and group therapy might also be quite different. From a traditional perspective, coaching is strongly grounded in work effectiveness and performance. Although some forms of coaching (e.g., the third-generation group coaching, see Stelter, 2014) may target meaning-making, value reflection and well-being, psychotherapy often focuses on wider life issues, such as how to achieve closeness with others, how to deal with fear or anxiety, and how to make contact and build and maintain satisfying relationships. Coaching usually takes a growth perspective while therapy is more about healing (Cremona, 2010), though this assumption also can be nuanced. While one aim in psychotherapy often is client stabilization (in the form of reduced symptoms or distress), coaching might use destabilization as an approach to "shake the participant" and activate the motivation for change and development (Crowe, 2017). Finally, the relationship between the therapist and the client on the one hand, and the coach and the coachee on the other, might differ in closeness, connectedness, and presence of emotionality (Britton, 2010; Crowe, 2017; Gelso, Williams, \& Fretz, 2014; Riva, Wachtel, \& Lasky, 2004). Despite the differences between group coaching 
and group therapy, we hypothesize that using therapeutic factors for analytic purposes can increase our understanding of the different aspects of the group coaching process.

\section{Self-Efficacy}

According to Bandura (1997, p. 3), “self-efficacy refers to beliefs in one’s capabilities to organize and execute the courses of action required to produce given attainments”. Selfefficacy is considered as a cognitive component that is constructed through interactions between behavior and personal and contextual factors (Bandura, 1997, 1986). Because these beliefs are assumed to have a direct psychological effect on an individual's cognition, motivation, and affective state, self-efficacy is assumed to influence an individual's goals, choices, decisions, efforts, and quality of performance, as well as persistence in solving tasks (Bandura 1997, 2006; McCormick, 2001; Zimmerman, 2000). In the domain of school leadership, self-efficacy has been conceptualized on a number of dimensions at various levels such as instructional leadership, economic leadership, administrative management, parental relations, managing the learning organization, school improvement, staff professional development, policy demands, and moral leadership (Federici \& Skaalvik, 2011; Petridou, Nicolaidou, \& Williams, 2014; Tschannen-Moran \& Gareis, 2004). Previous research has revealed that leadership self-efficacy is positively associated with job autonomy and proactive behavior (Den Hartog \& Belschak, 2012), work engagement (Federici \& Skaalvik, 2011), job satisfaction, personal accomplishment (Federici \& Skaalvik, 2012), and leaders’ trust in teachers and students (Tschannen-Moran \& Gareis, 2004), as well as trust in peer leaders (Brandmo, Tiplic, \& Elstad, 2019). On the other hand, self-efficacy is also found to be negatively associated with work alienation (Tschannen-Moran \& Gareis, 2004), emotional exhaustion, and turnover intentions (Federici \& Skaalvik, 2012). Given these qualities, a set of positive and well-calibrated self-efficacy beliefs seems to be important for effective leadership. 


\section{Role Clarity}

Role clarity refers to the sufficiency of information regarding the expectations associated with one’s role within the organization (Panaccio \& Vandenberghe, 2011). Previous research has shown that perceived role clarity is positively associated with learningcentered goal orientation (Brandmo, Tiplic, \& Elstad, 2014), self-efficacy for instructional leadership (Brandmo et al, 2019), collective efficacy (Tiplic, Brandmo, \& Elstad, 2015) and affective commitment to the organization (Allen \& Meyer, 1990; Tiplic, Brandmo, \& Elstad, 2015). Moreover, perceived role-clarity can be a resilience factor when the work tasks become demanding because it provides a sense of control over the situation (Bliese \& Castro, 2000). Furthermore, research indicates that a clear understanding of role expectations is positively related to perceived autonomy, adaption to change, planning activities, and facilitation of team work (Rizzo, House, \& Lirtzman, 1970). For leaders new to their positions, obviously, acquisition of role knowledge is important, but it is also very demanding, particularly when the role is complex, or the organizational context is very dynamic (Van Wart, 2011).

\section{The Context of the Current Study}

Since 2009, the University of Oslo has been one of the providers of the National Principal Program in Norway. The program is part-time (at the graduate level) for newly appointed school leaders. The content of the program is organized around five themes: students’ learning, management and administration, cooperation and organization building, development and change, and the leadership role (Hybertsen et al., 2014). Since one of the expectations is construction of a democratic but independent leadership role, the program design seeks to create opportunities for this development process. Accordingly, the program as a whole uses the participants' experiences as a starting point for professional learning and development. Over one and a half years, various methods are introduced to the participants to 
enhance critical thinking about their leadership practice. Group coaching that promotes reflections on personal agency (role clarity and self-efficacy) is an integrated part of the program (Aas \& Vavik, 2015).

\section{The Coaching Approach}

Three full days (of seven hours each) of the 20-day program are devoted to coaching. In the first session (day 1), the focus is on the leadership role, and the participants prepare for this session by conducting a $360^{\circ}$ feedback ${ }^{1}$ in their schools. In the second coaching session (day 2), the focus is on personal agency, which includes preparation by mapping their own competency profile and clarifying how to stimulate personal and competency growth. In the third coaching session (day 3), the focus is on how to further develop leadership skills and handle change initiatives (Bion, 1970; Britton, 2010).

Coaching is delivered to groups of six participants in a seminar room at the university and is led by a group coach who has participated in a joint training program at the University of Oslo. The group coaching approach emphasizes that participants (coachees) are the focus of the coaching process, while the other participants assist as co-coaches. In this approach, the participants take turns being coachees and about one hour is dedicated to each participant. To support the coaching process, a specific group coaching protocol has been developed, which includes rules and procedures for interactions among the participants, and time management procedures. This protocol has also been adopted for use in an international pilot by the Professional Learning through Reflection project promoted by Feedback and Coaching (PROFLEC) $)^{2}$ involving 10 countries (Flückiger et al., 2017).

The protocol was inspired by Brown and Grant’s (2010) goal, reality, options, understand others, perform (GROUP) model that builds on Whitmore’s (2002) goal, reality,

\footnotetext{
${ }^{1} 360^{\circ}$ refers to mapping of related employees' expectations of the leader. This mapping is typically conducted by interviewing a subordinate employee, a leader at the same level, and a superior.

${ }^{2} \mathrm{http}: / /$ www.bildungsmanagement.net/Proflec/index.htm
} 
options, way forward (GROW) model, and it takes into account that understanding others is the key factor in successful group conversations. The protocol consists of five steps: (1) the presentation of the coaching issue identified by the coachee; (2) questioning by the coach and the co-coaches (group members) to clarify the issue; (3) reflection by and advice from the coach and the co-coaches related to the issue; (4) reflections and responses from the coachee; and (5) summing up and decision-making regarding an action plan by the coachee. The coach takes a very active role by asking clarifying questions, summarizing information, introducing alternate perspectives, and offering suggestions. In the next section, we present how the implementation of the program was researched.

\section{Method}

In the current study, we collected two types of qualitative data, namely participants’ reflection notes related to each coaching, and the final written evaluation of the program. The results from both data sources were used to draw common conclusion. Collection and handling of all data in the current study met the requirements of the Personal Data Registers Act and were approved by the Norwegian Social Science Data Services. Participation were voluntary, and all data were anonymized before analyses. An overview of the data sources is displayed in Table 2.

\section{[Insert Table 2 about here]}

\section{Participants}

Overall, the results of the present study are based on data from the 77 participants (62\% female and 38\% male), representing two different groups of school leaders who completed the National Principal Program in December 2013. Geographically, the majority of participants were from the southeast part of Norway, the counties that surround the Oslo region (45\% from rural areas). Ages ranged from early 30s to late 50s; however, about 58\% were between 40 and 49 years old. Among the participants, 25\% were full-time principals, 9\% 
were part-time principals, 23\% full-time midlevel managers, 38\% were part-time midlevel managers, and 5\% had other leadership positions in school (e.g., vice principal, principal for studies). Thirty percent were employed in primary schools, $30 \%$ in combined primary and lower secondary schools, $20 \%$ in lower secondary schools, and 20\% in upper secondary education. Of these schools, 53\% were located in urban areas and $47 \%$ in rural areas. The participants’ leadership experience ranged from 0.5 year to 16 years with a mean of 6 years.

\section{Material}

Participants’ reflection notes. Immediately after every coaching session, the participants anonymously submitted their reflection notes, which detailed their experiences with the group coaching, to a digital learning platform. The aim of these reflections was twofold: to catch the participants' experiences of the coaching as a source of learning and then to induce a metareflection on the relevance of the coaching for their actual leadership role. To direct the feedback, the following questions were raised in the first session: (a) What became clearer for you today? (b) What were you inspired to look into further? (c) Were there topics that were of particular interest to you? (d) What is the relevance of the topics we discussed today for you in your job as a school leader? After the second and third coaching sessions, we reduced the questions to the following: (a) What became clearer for you today? (b) What is the relevance of the topics we discussed today for you in your job as a school leader?

Final evaluation. Three weeks after the last coaching session, the participants anonymously submitted a final evaluation to a digital learning platform. This evaluation contained standardized questions and two open questions where the participants were invited to provide comments about the program. The first open question was, "What components in the program have been significant for your learning?", and the second open question asked them to provide "other comments". In this study, we specifically analyzed the two open questions. 


\section{The Analytic Approach}

To analyze the qualitative data material, we conducted a content analysis (Silverman, 2011). Using Hyper Research software, we selected relevant comments from the participants’ reflections, as well as from the final evaluation. In the first wave, we focused on comments that could be connected to the participants' self-efficacy and issues related to understanding their leadership role. This process produced many comments that were further refined into the two main categories. Some of the comments fell into both main categories, for instance: “The coaching made me more secure on how I can influence my own working situation as well as how I can deal with sensitive personnel issues.” From these categories, we selected typical examples that could illustrate the participants' and understanding of their leadership role after they had participated in the program. The findings from this thematic analysis showed the participants described the outcome of the group coaching related to clarity and the relevance for their own job as school leader.

In the second wave of analyses, we followed the same approach; however, we used the 11 therapeutic factors as a framework for our analysis. More specifically, we selected statements that represented or linked to one or more of the 11 therapeutic factors. This analysis also revealed statements that we used as prototypical examples (presented in the results section).

\section{Results}

The presentation of the results is organized in two subsections. First, we present the results related to role clarity and self-efficacy, which address the first research question. In the second part, we present the results related to the usefulness of the therapeutic factor framework, which address the second research question.

\section{Role Clarity}


Most participants appreciated the possibility of exploring the school leader role during the group session. First, discussions with colleagues revealed various approaches to leadership, which seemed to cause an enhanced understanding of the leadership role for the coachee and the other participants. The feedback from the $360^{\circ}$ interviews and the preference profile (Jung, 1971) provided knowledge of other people’s expectations and their personal preference and contributed to reflections at the individual level. Second, the group sessions provided opportunities for collective reflections altering the participants' mental models and thinking, described as double loop learning (Argyris \& Schön, 1978), and with the possibilities of fundamental change in the participants' thinking and behavior, described as triple loop learning (Hargrove, 2008). An example of how the group process supported different types of reflections was expressed by a participant at the end of the program: I have increased understanding of my own strengths and weaknesses. It has been obvious to me that I have to prioritize between all the tasks the teachers expect me to do. I have to decide which leadership issues I will foreground, and I have to make plans for the future, not only take part in upcoming daily activities.

Several participants reported how reflections and advice in the group process offered useful examples of new actions to take. Britton (2010) contended that a key priority in group coaching is to hold participants accountable for taking steps to achieve their goals and integrate their learning in "real life.” The focus in the group sessions was relational issues, especially issues where the teachers were not satisfied with the leaders' decisions. The relational aspects of the leadership role seem to be the most challenging part for teachers becoming leaders. Many participants expressed concern about how to show empathy and support teachers while being able to make decisions when consensus is impossible (Louis, 2003). A participant observed: 
It has been clearer to me that I have to live with some criticism from teachers. I find it difficult because I want to be a good guy. After the group sessions, I realized that as a school leader I have to learn that it is not a person who is the problem, but it is more complex. I must stop beating myself up all the time.

\section{Self-Efficacy}

The notion of self-efficacy seems to be closely connected to role clarity. The participants come into the coaching sessions with various levels of self-efficacy derived from earlier experiences of personal competencies and social support. Understanding the role is a necessary step in constructing one’s own leadership identity (Aas \& Vavik, 2015). However, the participants reported on the importance of having knowledge about the leadership tasks, knowledge about the context where leadership is played out, and knowledge about the methods or tactics in resolving difficult situations (Dempster, Lovett, \& Fluckiger, 2011). Experimenting with new actions in daily life depends on the climate for change and a willingness to do it (Robertson \& Earl, 2014). Most participants acknowledged that the sharing process in group sessions supported them in holding and bringing paradoxes in leadership to the surface, such as thinking long-term vs. delivery of results now, encouraging innovation vs. avoiding mistakes, and being flexible vs. respect for the rules (Thornton, 2010). After the last coaching session, the data indicated that the sharing processes increased the participants’ self-efficacy (Bandura, 1977):

Through this program, and especially the coaching sessions, I have experienced the importance of working together and sharing with others. I have got an increased understanding of what this job is about and that makes me feel safer in my position as a school leader. Knowledge about the different work tasks and tools to handle problematic issues presented by colleges has given me strength to try new actions. 
The feedback on participants’ personal preferences (Jung, 1971) seem to enhance selfreflections and self-understanding aspects that were further developed in the group coaching. Most participants were motivated by working on how their personal competencies and behaviors could influence their own leadership within their school. Furthermore, the participants considered coaching to be an important medium for turning their formal (and informal) knowledge about leadership into practice (Huber, 2011; Kolb, 1984; Lewin, 1997; Revans, 1979). Even though most had gone through a rigorous recruitment process to become leaders, the feeling of not being good enough was a prominent issue in the coaching: I feel that there is a considerable gap between the confidence I seem to express and the uncertainty I feel inside me. Today I was particularly conscious that one should always think about "resistance forces" one more time and to take another more positive approach. You have to go alongside the staff, not fight against them. Then I have to work on my tendency to be impatient.

Similar quotes demonstrated how group coaching had the ability to stimulate reflection on the individual and collective levels (Britton, 2010), which probably led to increased role clarity and self-efficacy, as well as more awareness of their own choices and perspectives and potential actions (Bandura, 1986, 1997, 2000; Thornton, 2010). This process may be characterized as mirroring, which Thornton (2010) observed happens in at least four different ways: being seen, accepted, recognized, and acknowledged as oneself.

\section{The Therapeutic Factors}

In this section, we address the second research question about understanding the group coaching process in light of theory about psychotherapeutic factors. The findings revealed seven out of the 11 therapeutic factors. 
Installation of hope. Participants in the group coaching sessions shared their views, methods, and experiences with change initiatives in their school context. According to Yalom and Leszcz (2005), Cheliotes and Reilly (2010), and Perkins (2003), sharing reveals feelings of hope for the future. The participants' reflection notes and final evaluation revealed hope to accomplish their studies, as well as hope to implement new leadership actions in their own school. In the feedback, which occurred in the clarification and the reflection phase of the group session, the needs and values of others were recognized.

During the participants’ final evaluation of the group sessions, the importance of observation and sharing the successes and failures of other participants' change initiatives was revealed. One leader expressed how sharing views among colleagues contributed to the development of hope: “During the coaching, it was confirmed for me that my method of opening a rather closed organization has been quite successful. I have more belief in myself when it comes to choosing direction in my leadership.”

Universality. Many participants came to the coaching sessions thinking that their challenges, their school context, and their school’s history were unique. After listening to other participants' concerns and challenges, most of them realized that their experiences were not unique. Yalom and Leszcz (2005, p. 6) explained this phenomenon with the metaphor "We are all in the same boat.” Although the nature of leadership varies from one school to another depending on the context, common activities that reflect school leadership, nationally and internationally, can be identified (Rhodes \& Fletcher, 2013; Tolhurst, 2010). The participants in the leadership program had much in common, and first-hand experience in ways to cope with their roles provided a feeling of collegiality. One participant observed:

It helps a lot to talk to other leaders who are in the same position as I. I became humble when they described what they had been doing, but I see that much of it is the same that I also have been a part of. 
Another participant said, “Hearing about other leaders' challenges and daily life makes me think about my own practice, gives me new ideas about my own leadership preferences, and strengthens my self-efficacy.”

Imparting information. According to Yalom and Leszcz (2005), new information is provided in group therapy using didactic instruction or providing direct advice. Didactic instruction in the group coaching took various forms, explanation of processes, explanation of factors that may affect the processes, and sharing of alternative intervention opportunities. One participant described how didactic instruction led to new intervention opportunities as follows: “The cooperation between me and the principal is challenging. During the coaching, the other members had solutions for solving my problem, and how I could be a better communicator.” Another participant observed, “During the coaching, I got advice that made me more confident when it comes to how to deal with difficult and personnel issues and how to influence the development of the school as an organization.”

Direct advice from other participants occurred during every group coaching session without exception. More specifically, in the early stages of the group work, participants commented such as: “I think you ought to..., or, Why don’t you...?” According to Yalom and Leszcz (2005), to what extent direct advice benefits participants in the group is uncertain. However, advice-giving sequences suggest help and care are being provided, and many participants appreciated the advice given to them. One participant noted, "I was told that I have to be more direct an independent and have a talk with the inspector about the situation in the leadership team.” Another participant said, "You have to delegate administrative work to others, and not do everything yourself.”

Altruism. In group therapy, reciprocal giving-receiving sequences that include reflection on feedback, advice, and sharing experiences ensure participants gain through giving, not only in receiving from others (Zhu, Avolio, Riggio, \& Sosik, 2011). In this study, 
the participants perceived themselves as similar in experience and competence as leaders, and reciprocal giving-receiving sequences began immediately. The Understanding Others step in the coaching protocol is thinking together. According to Brown and Grant (2010), dialogue is a conversation in which the participants are open to possibilities, are prepared to let go of the need to be right, and during the process can change character. An example of the importance of reciprocal giving-receiving sequences is reported below:

It became clearer for me how the other group members thought about me as a leader. They gave response to how I affected them, and it is good to hear that even persons who seemed to be experienced and confident also can be insecure in themselves.

Imitate behavior. There is considerable evidence from the therapy field that therapists influence the communication patterns in the group by modeling certain behaviors (Hawkins \& Schwenk, 2010; Kivlighan, Lo Coco, \& Gullo, 2012; Kivlighan et al., 2010). The same influences were evident in the coaching groups in this study. Participants learned from other participants and from the group coach by watching one another tackling and sharing problems. One of the coachee explained: "I learn a lot from the other participants in my group and how I can coach them.”

Imitative behavior or model learning (Bandura, 1986) may have a strong impact when the participants feel the behavior fits their own personal competence. Several participants reported that one benefit of participating in the coaching sessions was learning the group coaching protocol. That means that imitating behavior also included knowledge about the methods in use, illustrated in the following:

My main leadership challenge is to create a learning environment in my own leadership team. I think I will adapt this coaching methodology to my own leadership 
team. After observing the coaching facilitator and being in positons as both coach and coachee, I feel I can be the coaching facilitator myself.

Interpersonal learning. Reading and handling social processes are vital school management skills (Lee, 2001). A coaching group is an opportunity for participants to give and receive constructive criticism/feedback and analyze social processes that arise or are presented in the group (Goleman, 2006; Goleman, Boyatzis, \& McKee, 2002). In the study, questions about self-behavior were used to help the participants increase interpersonal learning. Examples include the following: (a) Describe your behavior in this current situation. (b) How do you think that your behavior makes others feel? (c) How do you think your behavior influenced others’ opinions? One participant reflected on how the group coaching process provided opportunities for self-understanding and interpersonal learning: “After listening to the advice from the other leaders, I realized that I have to become better to handle criticism and to start with delegating tasks to others.”

Group cohesiveness. The literature shows that groups with high levels of cohesiveness have better outcomes (Yalom \& Leszcz, 2005). The importance of feeling warmth and comfort and a sense of belonging can be understood in the context of human development, particularly when the group participants receive feeling of acceptance and approval that is self-actualizing. Belonging to the group provides self-esteem and "meets members dependency needs ... that fosters responsibility and autonomy” (Yalom \& Leszcz, 2005, p. 75). Participants reported that the group feeling was critical for their sharing and learning process:

I am really surprised how fast it was established confidence in the group. It felt good to be in a group where we could share our personal leadership challenges without 
being afraid that our conversations would be shared outside the room. We plan to meet each other regularly also after finishing the program.

The findings, then, indicate that the participants gained a clearer picture of their own role, obligations, and the contextual expectations of them. In sharing their thoughts and experiences during the group coaching, they gained an awareness of alternative mindsets, as well as knowledge about alternative approaches to solving the challenges they experienced in their job as school leaders. Furthermore, drawing on Yalom and Leszcz's (2005) therapeutic factors framework, we identified seven out of eleven factors in our data: installation of hope, universality, imparting information, altruism, imitating behavior, interpersonal learning, and group cohesiveness.

\section{Discussion}

In this section, we first discuss the two research questions related to whether group coaching contributes to leaders' self-efficacy and role clarity and how psychotherapy might contribute to an understanding of the group coaching process. Finally, we present the limitations of the current study and provide suggestions for further research.

\section{The Contribution of Group Coaching to Leaders' Self-Efficacy and Role Clarity}

The results of reflection notes reported immediately after the coaching sessions and from the final evaluations indicated that the participants' awareness of their responsibilities as leaders increased. If we see development of role clarity as an ongoing process of construction and deconstruction (Aas \& Vavik, 2015), it can be explained by the interplay between acquired knowledge about the school leadership and the contextualization that happens during reflections and discussions in the coaching session. This can also be inferred as interplay 
between formal or ideal knowledge (a normative standard) and more practical knowledge about implementation (Huber, 2011).

Previous research indicates that engagement with leaders from diverse contexts provides opportunities to consider new ways of working as leaders (Lee, 2007). In our case, this may have been reinforced by the assignments the participants completed as preparation for coaching, particularly the $360^{\circ}$ mapping of role expectations. By bringing fresh information from their own organizations that was strongly linked to them, as persons and leaders, they were at a good point for introducing coaching issues that were current and relevant for them at that time. Consequently, the conversations, exchange of experiences, and the reflections in the coaching sessions became highly focused and appeared to be meaningful and important to the participants. As far as we can see, a successful move was to bring together school leaders that had much in common, who were relatively new in their leadership positions and shared many of the same worries, but still came from diverse school contexts with a variety of experiences. The composition of the groups gave the coachees opportunities to reframe their understanding of situations and issues, to have more options and ideas for solving various problems, and to develop alternative ways to organize their leadership activities. Given these observations, a particular outcome of this type of coaching might be the strengthening of practical leadership knowledge, as well as contextual or situational knowledge which, in turn, is considered crucial for an adaptive and well-prepared leadership (Heifetz, Linsky, \& Grashow, 2009).

Self-efficacy is important in school leadership as self-motivation, and it promotes greater efforts, persistence, and a potential to achieve more. In the coaching sessions, issues related to governance and personnel management were particularly frequently considered problem areas along with issues of how to best organize their various work-related obligations. Regarding the self-efficacy building process, Bandura $(1977,1997)$ emphasized 
four sources to self-efficacy: enactive experience, vicarious experience (mastery by others), verbal persuasion, and a psychological and affective state. Enactive experience, which is the experience one earns from previous actions, is, according to Bandura (1997), the most powerful factor contributing to self-efficacy. In the group coaching sessions, vicarious experiences and verbal persuasions were presented when the participants were given the opportunity to their share experiences with the other leaders. This sharing of experiences, as well as their conversations, can be associated with the therapeutic factors of universality (i.e., members recognize that other members share similar feelings, thoughts, and problems) and imparting information (i.e., knowledge about how school leadership can be performed in different settings), which are crucial for developing self-understanding and contextual understanding. Therefore, we suggest that developing self-efficacy for school leadership is closely connected to sharing experiences and reflections related to daily leadership practice.

In the literature, an improved systemic awareness of the organization and an increased understanding of others are acknowledged as significant benefits of the group coaching technique (Brown \& Grant, 2010). In our data, we found some evidence for increased commitment from the participants to their school organization. A reasonable explanation is that reflections related to their own organization made while in the coaching groups (e.g., with information from the $360^{\circ}$ mapping) contributed to deeper and more consistent insight into the participants’ own school organizations. According to the coaching literature, system-level thinking is an advantage of group interventions (Britton, 2015; Brown \& Grant, 2010; Thornton, 2010; Tolhurst, 2010), and research in the business sector has demonstrated how team coaching can support cultural change in the organization (Anderson, Anderson, \& Mayo, 2008). Kets de Vries (2005) has also emphasized that group coaching is more effective than dyadic coaching because group coaching deals with cognitive reflections that affect the organization rather than focusing on individual goal achievement. Our experiences indicate 
that linking assignments or preparation work, with a basis in their own organization, to the group coaching might be fruitful because it tends to lift the content and focus of the group coaching. The focus would not be on the individual leaders' more narrow challenges only or on organizational issues only, but it would include attention to the relations between the leader and the organization. A positive consequence of this, in turn, might be a stronger commitment to the organization.

\section{Therapeutic Factors as a Framework for Understanding Group Coaching}

The analysis of the participants' reflections and the final evaluation identified seven of the 11 therapeutic factors (Yalom \& Leszcz, 2005). The factors interpersonal learning and group cohesiveness appear to be fundamental in the development of the other factors. A safe and inclusive group environment may be a precondition for change and something necessary to develop factors such as installation of hope, universality, imparting information, altruism, and imitate behavior. Britton (2010), Brown and Grant (2010), and Tolhurst (2010) suggested that building trust and support within coaching is important, and the aforementioned factors may be helpful in elaborating how change depends on relationships among the participants at the cognitive, behavioral, and emotional levels (Fletcher, 2012).

Scamardo and Harnden (2007) found that five of the 11 therapeutic factors (installation of hope, universality, imparting information, altruism, and imitate behavior) supported the development of interpersonal skills or relational skills. The current study adds two factors to Scamardo and Harnden’s findings: interpersonal learning and group cohesiveness. According to Yalom and Leszcz (2005), interpersonal learning and group cohesiveness are mainly emotional factors. This means that emotions seem to be significant in establishing a safe and inclusive group environment and a necessary precondition for developing new thinking and behaviors among the participants. Also, this study did confirm that the different factors are not discrete but are intermeshed with each other as well as with 
other processes such as raising self-efficacy (Liu \& Phillips, 2011). Further, the interplay among the different factors seems to support not only the development of interpersonal and relational skills but also an increased understanding of the leadership role.

The factors related to the corrective recapitulation of the primary family group, the development of socializing techniques, and catharsis were absent in our data, while the existential factor sometimes was present when the school leaders discussed career questions. There are several possible reasons why these factors were not present. For example, some factors were less relevant for the topics raised in coaching, such as the corrective recapitulation of the primary family group. Another explanation is that it related to how the data was collected, and because we did not ask for particular issues that related to the therapeutic factors. For instance, one can imagine that a discussion in the group coaching could include or lead to the development of socializing techniques.

Given the limitations of the data content and format of this study, it was not possible to delve deeper into the core areas of these factors. Although some scholars might view it as controversial, we believe that the results of this study illustrate that "crossing the road" into related fields, such as therapy and group therapy, can be beneficial and fruitful for further developing the coaching field. At the same time, we would like to emphasize that we do not mean that coaches should conduct therapy (unless the situation is appropriate, they have relevant background, and are trained for it). Our motivation was purely theoretical, namely, to borrow theories from the therapeutic field to elaborate and understand the processes that go on in group coaching. From our point of view, the theory of therapeutic factors may represent a useful starting point and contribute to the creation of a potential framework that can more fully explore the processes that exist in group coaching. Some of these factors ought to be further elaborated upon and adapted into the context of group coaching, while others show less relevance. Another kind of data, such as process data, which can illustrate events and 
interpersonal interactions online, may better encapsulate this framework's potential and, in turn, help us conceptualize and understand the processes that occur in group coaching

\section{Limitations and Further Research}

A limitation concerns the generalizability of the current study. The results are based on a small nonrandom sample. The study, therefore, should be considered as an explorative case study instead of generalizable evidence.

A second limitation is related to the variation in the material. We did not find any negative statement concerning the group coaching. Rather, many participants emphasized group coaching as the most significant learning event in the program.

A third limitation is that taking an individual perspective on the effects of group coaching assumes that participants' outcome is a function of the mutual group effect (Kivlighan et al., 2010). In the future, new research methods for exploring the group effect from both individual and group perspectives should be developed. Thus, additional explorative studies as well as effect studies are needed to gain new knowledge about group coaching and to show its effect on leadership.

\section{Conclusion}

The aim of the study was to examine whether group coaching contributed self-efficacy and role clarity among school leaders and to explore whether and how psychotherapy theory can contribute to our understanding of the group coaching process. Based on a sample of participants from the National Principal Training Program at the University of Oslo, we found evidence that group coaching can promote self-efficacy and role clarity among school leaders. In addition, we contend that the current form of group coaching, "a facilitated group process that is led by a professional coach and formed with the intention of maximizing the combined energy, experience and wisdom of individuals” (Cockerham in Britton, 2010, p. 6), is important for gaining participants' practical knowledge about leadership implementation. 
The current study also reveals that factors identified in psychotherapy can be a useful analytical tool for studying processes that are involved in group coaching. Inclusion of emotional aspects, such as those involved in interpersonal learning and group cohesiveness, is important and is a crucial part of the foundation for developing the participants' self-efficacy and role clarity.

Regarding practical implications, we assume that increased role understanding (expectations and obligations), strengthening one's self-efficacy (belief that one can manage various situations), and improvement of practical knowledge (how to solve various leadership challenges) can promote school leaders' enactment of change. Furthermore, we assume that the process-knowledge and procedures learned through group coaching may enrich the school leaders' repertoire of management approaches. Leadership from a facilitator's perspective may be a relevant and fruitful strategy for several contexts and situations. 


\section{References}

Aas, M., \& Vavik, M. (2015). Group coaching: A new way of constructing leadership identity? School Leadership \& Management, 35(3), 251-265. doi:10.1080/13632434.2014.962497

Allen, N. J., \& Meyer, J. P. (1990). The measurement and antecedents of affective, continuance and normative commitment to the organization. Journal of Occupational Psychology, 63(1), 1-18. doi: 10.1111/j.2044-8325.1990.tb00506.x

Anderson, M. C., Anderson, D. L., \& Mayo, W. D. (2008). Team coaching helps a leadership team drive cultural change at Caterpillar. Global Business and Organizational Excellence, 27(4), 40-50. doi:doi:10.1002/joe.20212

Argyris, C., \& Schön, D. A. (1978). Organizational learning a theory of action perspective. Reading, MA: Addison-Wesley.

Bachkirova, T., Spence, G., \& Drake, D. (Eds.). (2017). The Sage handbook of coaching. London: Sage.

Bandura, A. (1977). Self-efficacy: Toward a unifying theory of behavioral change. Psychological Review, 84(2), 191-215. doi: 10.1037/0033-295x.84.2.191

Bandura, A. (1986). Social foundations of thougt and action: A social cognitive theory. Upper Saddle River, NJ: Prentice Hall.

Bandura, A. (1997). Self-efficacy, the exercise of control. New York: W.H. Freeman and Company.

Bandura, A. (2000). Exercise of human agency through collective efficacy. Current Directions in Psychological Science, 9(3), 75-78. doi: 10.1111/1467-8721.00064 Bandura, A. (2006). Adolecent development from an agentic perspective. In F. Pajares \& T. Urdan (Eds.), Self-efficacy beliefs of adolescents (pp. 1-43). Greenwich, CT: IAP. Bion, W. (1970). Attention and interpretation. London: Karnac. 
Bliese, P. D., \& Castro, C. A. (2000). Role clarity, work overload and organizational support: Multilevel evidence of the importance of support. Work \& Stress, 14(1), 65-73. doi: $10.1080 / 026783700417230$

Bloch, S., Crouch, E., \& Reibstein, J. (1981). Therapeutic factors in group psychotherapy: A review. Archives of General Psychiatry, 38(5), 519-526. doi:10.1001/archpsyc.1980.01780300031003

Brandmo, C., Tiplic, D., \& Elstad, E. (2014). The achievement goal theory as an approach to study school principals' leadership motivation. Problems of Education in the 21st Century, 58, 27-38.

Brandmo, C., Tiplic, D., \& Elstad, E. (Online, 2019). Antecedents of department heads’ job autonomy, role clarity, and self-efficacy for instructional leadership. International Journal of Leadership in Education, 1-21. doi:10.1080/13603124.2019.1580773

Britton, J. J. (2010). Effective group coaching. Tried and tested tools and resources for optimum coaching results. Hoboken, NJ: Wiley.

Britton, J. J. (2015). Expanding the coaching conversation: Group and team coaching. Industrial and Commercial Training, 47(3), 116-120. doi:10.1108/ict-10-2014-0070

Brown, S. W., \& Grant, A. M. (2010). From GROW to GROUP: Theoretical issues and a practical model for group coaching in organisations. Coaching: An International Journal of Theory, Research and Practice, 3(1), 30-45.

doi:10.1080/17521880903559697

Cheliotes, L. G., \& Reilly, M. F. (2010). Coaching conversations: Transforming your school, one conversation at a time. Thousand Oaks, CA: Corwin.

Clutterbuck, D. (2007). Coaching the team at work. London - Boston: Nicholas Brealey Publishing. 
Cockerham, G. (2011). Group coaching: A comprehensive blueprint. Bloomington, IN: iUniverse

Cremona, K. (2010). Coaching and emotions: An exploration of how coaches engage and think about emotion. Coaching: An Interantional Journal of Theory, Research and Practice, 3(1), 46-59. doi:10.1080/17521880903580073

Crow, T. (2017). Coaching and psychotherapy. In T. Bachkirova, G. Spence, \& D. Drake (Eds.), The Sage handbook of coaching (pp. 85-101). London: Sage.

Dempster, N., Lovett, S., \& Fluckiger, B. (2011). Content and strategies to develop school leadership: A select literature review. Melbourne: The Australian Institute for Teaching and School Leadership.

Den Hartog, D. N., \& Belschak, F. D. (2012). When does transformational leadership enhance employee proactive behavior? The role of autonomy and role breadth self-efficacy. Journal of Applied Psychology, 97(1), 194-202. doi: 10.1037/a0024903

Drake, D, \& Pritchard, J. (2017). Coaching for organization development. In T. Bachkirova, G. Spence, \& D. Drake (Eds.), The Sage handbook of coaching (pp. 159-175). London: Sage.

Federici, R., \& Skaalvik, E. (2011). Principal self-efficacy and work engagement: Assessing a norwegian principal self-efficacy scale. Social Psychology of Education, 14(4), 575600. doi:10.1007/s11218-011-9160-4

Federici, R., \& Skaalvik, E. (2012). Principal self-efficacy: Relations with burnout, job satisfaction and motivation to quit. Social Psychology of Education, 15(3), 295-320. doi: 10.1007/s11218-012-9183-5

Fletcher, S. J. (2012). Coaching: An overview. In S. J. Fletcher \& C. A. Mullen (Eds.), The Sage handbook of mentoring and coaching in education (pp. 24-40). London: Sage. 
Fletcher, S. J., \& Mullen, C. A. (2012). The Sage handbook of mentoring and coaching in education. London: Sage

Flückiger, B., Aas, M., Nicolaidou, M., Johnson, G., \& Lovett, S. (2017). The potential of group coaching for leadership learning. Professional Development in Education, 43(4), 612-629. doi:10.1080/19415257.2016.1223736

Gelso, C. J., Williams, E. N., \& Fretz, B. R. (2014). Counseling psychology (3 ed.). Washington D.C.: American Pyschological Association.

Gjesdal, S., Wold, B., \& Ommundsen, Y. (2018). Promoting additional activity in youth soccer: A half-longitudinal study on the influence of autonomy-supportive coaching and basic psychological need satisfaction. Journal of Sports Sciences, 37(3), 268-276. doi:10.1080/02640414.2018.1495394

Goff, P., Guthrie, E., Goldring, E., \& Bickman, L. (2014). Changing principals’ leadership through feedback and coaching. Journal of Educational Administration, 52(5), 682704. doi:10.1108/JEA-10-2013-0113

Goleman, D. (2006). Social intelligence: The new science of human relationships. New York, NY: Bantam Books.

Goleman, D., Boyatzis, R. E., \& McKee, A. (2002). The new leaders: Transforming the art of leadership into the science of results. London: Little, Brown.

Grant, A. M. (2007). Past, present and future: The evolution of professional coaching and coaching psychology. In S. Palmer \& A. Whybrow (Eds.), Handbook of coaching psychology: A guide for practitioners (pp. 23-39). New York: Routledge.

Hargrove, R. A. (2008). Masterful coaching field-book (3rd ed.). San Francisco, CA: JosseyBass Pfeiffer. 
Hawkins, P., \& Schwenk, G. (2010). The interpersonal relationship in the training and supervision of coaches. In S. Palmer \& A. McDowell (Eds.), The coaching relationships: Putting people first (pp. 203- 221). East Sussex, UK: Routledge.

Heifetz, R. A., Grashow, A., \& Linsky, M. (2009). The practice of adaptive leadership: Tools and tactics for changing your organization and the world. Bosten, MA: Harvard Business Press.

Huber, S. G. (2011). Leadership for learning - learning for leadership: The impact of professional development. In T. Townsend \& J. MacBeath (Eds.), Springer International handbook of leadership for learning. Springer international handbooks of education 25 (pp. 635-652). Dordrecht, the Netherlands: Springer.

Huff, J., Preston, C., \& Goldring, E. (2013). Implementation of a coaching program for school principals: Evaluating coaches' strategies and results. Educational Management, Administration \& Leadership, 41, 504-526. doi:10.1177/1741143213485467

Hybertsen, I. D., Stensaker, B., Federici, R. A., Olsen, M. S., Solem, A., \& Aamodt, P. O. (2014). Evalueringen av den nasjonale rektorutdanningen [The evaluation of the National Principal Program]. Oslo, Norway: NIFU, NTNU.

Jung. C. (1971). Psychological types. Princeton, NY: Princeton University Press.

Kets de Vries, M. F. R. (2005). Leadership group coaching in action: The zen of creating high performance teams. Academy of Management Executive, 19(1), 61-76.

Kivlighan, D. M. J., \& Holmes, S. E. (2004). The importance of therapeutic factors: A typology of therapeutic factors studies. In J. L. DeLucia-Waack, D. A. Gerrity, C. R. Kalonder, \& M. T. Riva (Eds.), Handbook of group counseling and psychotherapy (pp. 23-36). Thousand Oaks, CA: Sage. 
Kivlighan, D. M. J., Lo Coco, G., \& Gullo, S. (2012). Attachment anxiety and avoidance and perceptions of group climate: An actor-partner interdependence analysis. Journal of Counseling Psychology, 59(4), 518-527. doi:10.1037/a0030173

Kivlighan, D. M. J., Miles, J. R., \& Paquin, J. D. (2010). Therapeutic factors in group counseling: Asking new questions. In R. Conyne (Ed.), The Oxford handbook of group counseling (pp. 121-136). New York, NY: Sage.

Kolb, D. A. (1984). Experiential learning experience as the source of learning and development. Englewood Cliffs, NJ: Prentice-Hall.

Korotow, K. (2017). Coaching for leadership development. In T. Bachkirova, G. Spence, \& D. Drake (Eds.), The Sage handbook of coaching (pp. 139-158). London: Sage.

Law, H., Ireland, S.,\& Hussain, Z. (2007). The psychology of coaching, mentoring and learning. West Sussex, England: Wiley.

Lee, G. (2001). The relationship dimension in management development. Organisations and People, 8(3), 32-40.

Lee, G. (2007). Leadership coaching: From practical insight to organisational performance. London: Chartered Institute of Personnel and Development.

Lewin, K. (1997). Resolving social conflicts \& field theory in social science. Washington, DC: American Psychological Association.

Liu, Y., \& Phillips, J. P. (2011). Examining the antecedents of knowledge sharing in facilitation team innovativeness from a multilevel perspective. International Journal of Information Management, 31(1), 44-52. doi:10.1016/j.ijinfomgt.2010.05.002

Louis, K. S. (2003). Democratic schools, democratic communities: Reflections in an international context [Special issue]. Leadership and Policy in Schools, 2(2), 93-108. doi:10.1076/lpos.2.2.93.15544

Maslow, A. H. (1968). Towards a psychology of being. New York: D. Van Nostrand 
Mavrogordato, C., \& Cannon, M. (2009). Coaching principals: A model for leadership development. Paper presented at the annual meeting of the University Council of Educational Administration, Anaheim, CA.

McCormick, M. J. (2001). Self-efficacy and leadership effectiveness: Applying social cognitive theory to leadership. Journal of Leadership \& Organizational Studies, 8(1), 22-33. doi: 10.1177/107179190100800102

McRobert, C., Burlingame, G., \& Hoag, M. (1998). Comparative efficacy of individual and group psychotherapy: A meta-analytic perspective. Group dynamics. Theory, Research, and Practice, 2(2), 101-117. doi: 10.1037/1089-2699.2.2.101

O'Connor, S, \& Cavanagh, M. (2017). Group and team coaching. In T. Bachkirova, G. Spence, \& D. Drake (Eds.), The Sage handbook of coaching (pp. 486-504). London: Sage.

Panaccio, A., \& Vandenberghe, C. (2011). The relationships of role clarity and organizationbased self-esteem to commitment to supervisors and organizations and turnover intentions. Journal of Applied Social Psychology, 41(6), 1455-1485. doi: 10.1111/j.1559-1816.2011.00764.x

Palmer, S., \& Whybrow, A. (Eds.) (2007). Handbook of coaching psychology: A guide for practitioners. New York: Routledge.

Parker, P. (2017). Coaching for role transition/career change. In T. Bachkirova, G. Spence, \& D. Drake (Eds.), The Sage handbook of coaching (pp. 419-438). London: Sage.

Perkins, D. (2003). King Arthur's round table: How collaborative conversations create smart organizations. Hoboken, NJ: Wiley.

Revans, R. W. (1979). The nature of action learning. Management Learning, 10(3), 10-23. doi:10.1016/0305-0483(81)90061-X 
Rhodes, C. (2012). Mentoring and coaching for leadership development in schools . In S. J. Fletcher \& C. A. Mullen (Eds.), The Sage handbook of mentoring and coaching in education (pp. 243-256). London: Sage.

Rhodes, C., \& Fletcher, S. (2013). Coaching and mentoring for self-efficacious leadership in schools. International Journal of Mentoring and Coaching in Education, 2(1), 47-63. doi:10.1108/20466851311323087

Riva, M. T., Wachtel, M., \& Lasky, G. B. (2004). Effective leadership in group counseling and psychotherapy, research and practice. In J. L. DeLucia-Waack, D. A. Gerrity, C. R. Kalonder, \& M. T. Riva (Eds.), Handbook of group counseling and psychotherapy (pp. 37-48). Thousand Oaks, CA: Sage.

Rizzo, J. R., House, R. J., \& Lirtzman, S. I. (1970). Role conflict and ambiguity in complex organizations. Administrative Science Quarterly, 15(2), 150-163. doi:10.2307/2391486

Robertson, J., \& Earl, L. M. (2014). Leadership learning: Aspiring principals developing the dispositions that count. Journal of Educational Leadership, Policy and Practice, 29(2), 3-17.

Ryom, K., Andersen, M. M., \& Stelter, R. (2017). Coaching at-risk youth in a school within a socially challenging environment. Improving Schools, 20(2), 143-160. doi:10.1177/1365480217694955

Scamardo, M., \& Harnden, S. C. (2007). A manager coaching group model. Journal of Workplace Behavioral Health, 22(2-3), 127-143. doi: 10.1300/J490v22n02_09

Silver, M., Lochmiller, C. R., Copland, M. A., \& Tripps, A. M. (2009). Supporting new school leaders: findings from a university based leadership coaching program for new administrators. Mentoring \& Tutoring: Partnership in Learning, 17(3), 215-232. 
Silverman, D. (2011). Interpreting Qualitative Data (4 ed.). Thousand Oaks: Sage Publications.

Smith, C. L. (2017). Coaching for resilience and well-being. In T. Bachkirova, G. Spence, \& D. Drake (Eds.), The Sage handbook of coaching (pp. 346-362). London: Sage.

Stelter, R. (2014). A guide to third generation coaching - Narrative-collaborative theory and practice. Dordrecht, The Netherlands: Springer.

Stelter, R., Nielsen, G., \& Wikman, J. M. (2011). Narrative-collaborative group coaching develops social capital - a randomised control trial and further implications of the social impact of the intervention. Coaching: An International Journal of Theory, Research and Practice, 4(2), 123-137. doi:10.1080/17521882.2011.598654

Thornton, C. (2010). Group and team coaching. The essential guide. New York, NY: Routledge.

Tiplic, D., Brandmo, C., \& Elstad, E. (2015). Antecedents of Norwegian beginning teachers’ turnover intentions. Cambridge Journal of Education, 45(4), 451-474. doi:10.1080/0305764X.2014.987642

Tolhurst, J. (2010). The essential guide to coaching and mentoring (2nd ed.). Harlow, England: Pearson Education.

Tschannen-Moran, M., \& Gareis, C. R. (2004). Principals' sense of efficacy: Assessing a promising construct. Journal of Educational Administration, 42(5), 573-585. doi: doi:10.1108/09578230410554070

Tschannen-Moran, B., \& Tschannen-Moran, M. (2010). Evocative coaching: Transforming schools one conversation at a time. San Francisco, CA: Jossey-Bass

Vinogradow, S., \& Yalom, I. D. (1989). A concise guide to group psychotherapy. Washington, DC: American Psychiatric Press.

Van Wart, M. (2011). Dynamics of leadership in public service (2 ed.). New York: Routledge. 
Watling, P., \& Gasper, M. (2012). Dialogical mentoring and coaching in every years leadership. In S. J. Fletcher \& C. A. Mullen (Eds.), The Sage handbook of mentoring and coaching in education (pp. 257-272). London: Sage.

Whitmore, J. (2002). Coaching for performance: GROWing people, performance, and purpose. London: Brealy.

Whitmore, J. (2009). Business coaching international: Unlocking the secrets and the power. Coaching: An International Journal of Theory, Research and Practice, 2(2), 176-179. doi:10.1080/17521880903102332

Wolever, R., Moore, M., \& Jordan, M. (2017). Coaching in healthcare. In T. Bachkirova, G. Spence, \& D. Drake (Eds.), The Sage handbook of coaching (pp. 521-543). London: Sage.

Yalom, I. D., \& Leszcz, M. (2005). The theory and practice of group psychotherapy. New York, NY: Basic Books.

Zhu, W., Avolio, B. J., Riggio, R. E., \& Sosik, J. J. (2011). The effect of authentic transformational leadership on follower and group ethics. The Leadership Quarterly, 22, 801-817. doi:10.1016/j.leaqua.2011.07.004

Zimmerman, B. J. (2000). Self-efficacy: An essential motive to learn. Contemporary Educational Psychology, 25(1), 82-91. doi: 10.1006/ceps.1999.1016 
Table 1

The eleven therapeutic factors (Yalom and Leszcz 2005, pp. 1-19)

\begin{tabular}{|c|c|c|}
\hline \multicolumn{2}{|c|}{ Factor name } & \multirow{2}{*}{$\begin{array}{l}\text { Explanation } \\
\text { You are not alone and isolated with your issues - and } \\
\text { earn hope. }\end{array}$} \\
\hline 1) & Installation of hope & \\
\hline 2) & Universality & $\begin{array}{l}\text { Members recognize that other members share similar } \\
\text { feelings, thoughts and problems. }\end{array}$ \\
\hline 3) & Imparting information & $\begin{array}{l}\text { Education and advice given by the therapist/coach or } \\
\text { group members. }\end{array}$ \\
\hline 4) & Altruism & The act of giving without expecting anything in return. \\
\hline 5) & $\begin{array}{l}\text { The corrective recapitulation } \\
\text { of the primary family group }\end{array}$ & $\begin{array}{l}\text { Correctively relive early family conflicts, and } \\
\text { relationships that inhibited growth. }\end{array}$ \\
\hline 6) & $\begin{array}{l}\text { Development of socializing } \\
\text { techniques }\end{array}$ & $\begin{array}{l}\text { Obtain sophisticated social skills, as they learn how to } \\
\text { process emotions, resolve conflicts with others, to be } \\
\text { helpful, less judgmental of others and more empathetic. }\end{array}$ \\
\hline 7) & Imitate behavior & $\begin{array}{l}\text { Observing others growing skills that can be used in } \\
\text { their lives outside. }\end{array}$ \\
\hline 8) & Interpersonal learning & $\begin{array}{l}\text { Experiencing corrective emotional experiences within } \\
\text { and group which is a social microcosm. }\end{array}$ \\
\hline 9) & Group cohesiveness & $\begin{array}{l}\text { Allows members to feel the warmth and comfort of } \\
\text { being part of a group. }\end{array}$ \\
\hline 10) & Catharsis & $\begin{array}{l}\text { Occurs when an individual can express their deep } \\
\text { emotional feelings and experience a release and } \\
\text { healing. }\end{array}$ \\
\hline 11) & Existential factors & $\begin{array}{l}\text { Recognizes that life can be unfair and unjust at times, } \\
\text { that there is no escape from pain, that no matter how } \\
\text { close we get to other individuals we are ultimately } \\
\text { alone, and that there is no escape from the inevitability } \\
\text { of death. }\end{array}$ \\
\hline
\end{tabular}


Table 2

Overview of Data Sources

\begin{tabular}{llll}
\hline Data source & $\begin{array}{l}\text { Time of data } \\
\text { collection }\end{array}$ & Participants & $\begin{array}{l}\text { Response } \\
\text { rate \% }\end{array}$ \\
\hline Reflection paper after coaching session 1 & January & 63 & 82 \\
Reflection paper after coaching session 2 & May/June & 61 & 79 \\
Reflection paper after coaching session 3 & October & 51 & 66 \\
Final evaluation & November & 56 & 73
\end{tabular}

